University of Nebraska - Lincoln

DigitalCommons@University of Nebraska - Lincoln

Faculty Publications - Chemistry Department Published Research - Department of Chemistry

2010

The growth and evolution of thin oxide films on 8-plutonium surfaces

Harry G. García Flores

University of Nebraska - Lincoln

David L. Pugmire

University of Nebraska-Lincoln, pugmire@ornl.gov

Follow this and additional works at: https://digitalcommons.unl.edu/chemfacpub

Part of the Chemistry Commons

García Flores, Harry G. and Pugmire, David L., "The growth and evolution of thin oxide films on סplutonium surfaces" (2010). Faculty Publications -- Chemistry Department. 31.

https://digitalcommons.unl.edu/chemfacpub/31

This Article is brought to you for free and open access by the Published Research - Department of Chemistry at DigitalCommons@University of Nebraska - Lincoln. It has been accepted for inclusion in Faculty Publications -Chemistry Department by an authorized administrator of DigitalCommons@University of Nebraska - Lincoln. 


\title{
The growth and evolution of thin oxide films on $\delta$-plutonium surfaces
}

\author{
Harry G García Flores ${ }^{1,2}$ and David L Pugmire ${ }^{1,2}$ \\ ${ }^{1}$ Department of Chemistry, University of Nebraska - Lincoln, Lincoln, NE 68588- \\ 0304 USA \\ ${ }^{2}$ Materials Science \& Technology Division, Los Alamos National Laboratory, Los \\ Alamos, NM 87545 USA \\ E-mail: dpugmire@lanl.gov
}

\begin{abstract}
The common oxides of plutonium are the dioxide $\left(\mathrm{PuO}_{2}\right)$ and the sesquioxide $\left(\mathrm{Pu}_{2} \mathrm{O}_{3}\right)$. The nature of an oxide on plutonium metal under air at room temperature is typically described as a thick $\mathrm{PuO}_{2}$ film at the gas-oxide interface with a thinner $\mathrm{Pu}_{2} \mathrm{O}_{3}$ film near the oxide-metal substrate interface. In a reducing environment, such as ultra high vacuum, the dioxide $\left(\mathrm{Pu}^{4+} ; \mathrm{O} / \mathrm{Pu}=2.0\right)$ readily converts to the sesquioxide $\left(\mathrm{Pu}^{3+} ; \mathrm{O} / \mathrm{Pu}=1.5\right)$ with time. In this work, the growth and evolution of thin plutonium oxide films is studied with $\mathrm{X}$-ray photoelectron spectroscopy (XPS) under varying conditions. The results indicate that, like the dioxide, the sesquioxide is not stable on a clean metal substrate under reducing conditions, resulting in substoichiometric films $\left(\mathrm{Pu}_{2} \mathrm{O}_{3-\mathrm{y}}\right)$. The $\mathrm{Pu}_{2} \mathrm{O}_{3-\mathrm{y}}$ films prepared exhibit a variety of stoichiometries $(\mathrm{y} \sim 0.2-1)$ as a function of preparation conditions, highlighting the fact that caution must be exercised when studying plutonium oxide surfaces under these conditions and interpreting resulting data.
\end{abstract}

\section{Introduction}

The oxidation of plutonium metal continues to be an area of considerable activity. It is likely to remain so as long as the stability of this actinide metal continues to puzzle investigators. While the oxidation states, stoichiometries and crystallographic structure of plutonium oxides in the bulk powder form have been studied and elucidated, the body of knowledge regarding the nature of oxide films on the metal surface is not as extensive. Traditionally, the stable oxides of plutonium at room temperature have been thought to be plutonium sesquioxide $\left(\mathrm{Pu}_{2} \mathrm{O}_{3}, \mathrm{Pu}^{3+}\right)$ and plutonium dioxide $\left(\mathrm{PuO}_{2}, \mathrm{Pu}^{4+}\right)[1-$ 4]. A recent study of the possibility of hyper-stoichiometric oxides of plutonium [5] concluded that $\mathrm{PuO}_{2+\mathrm{x}}$, while present at the surface, is not stable as a bulk phase. In another study, the instability of $\mathrm{PuO}_{2}$ films on plutonium metal substrates, as evaluated by the metal oxidation state transformation $\left(\mathrm{Pu}^{4+}\right.$ to $\left.\mathrm{Pu}^{3+}\right)$ in a reducing environment, was evaluated [6]. From this work, a diffusion coefficient for oxygen through plutonium sesquioxide was obtained.

Surface-sensitive techniques, typically under ultra high vacuum (UHV) conditions, are often used for the study of the surface chemistry and electronic properties of plutonium and its oxides. In order to accurately understand and interpret results, a detailed knowledge of how these surfaces are prepared and how they behave under a variety of conditions is required. We report here how preparation 
conditions of thin oxide films on plutonium metal affect the resulting surface, as well as results that indicate some stoichiometric instability of thin $\mathrm{Pu}_{2} \mathrm{O}_{3}$ films on clean plutonium metal.

\section{Experimental}

The work presented here was carried out on a Kratos Axis Ultra XPS instrument with a typical base pressure of $5 \times 10^{-10}$ Torr. Data was acquired using a monochromatic Al K $\alpha$ radiation source (1486.7 $\mathrm{eV})$. The poly-crystalline sample used for this study was high-purity ( 160 atomic ppm C), electrorefined plutonium, stabilized in the $\delta$ phase with gallium $(\sim 2$ atom $\% \mathrm{Ga})$. This sample was cleaned with repeated cycles of argon ion sputtering and annealing $\left(450{ }^{\circ} \mathrm{C}\right)$ until the carbon and oxygen signals were below the limits of detection for these transitions. The sample was oxidized by introduction of $\mathrm{O}_{2}$ (Scotty Specialty Gases, 99.99\%) into the vacuum chamber. All data analysis was performed with CasaXPS software using a Shirley-type background [7]. Binding energies for all data sets were adjusted to set the $\mathrm{Pu} 4 \mathrm{f}_{7 / 2}$ transition for the $3+$ species at $424.4 \mathrm{eV}$. This resulted in observed $\mathrm{Pu} 4 \mathrm{f}_{7 / 2}$ transitions at $426.0 \mathrm{eV}$ for the $4+$ species and $422.0 \mathrm{eV}$ for the metal, as well as $\mathrm{O} 1 \mathrm{~s}$ transitions at $530.0 \mathrm{eV}$ for the sesquioxide $529.8 \mathrm{eV}$ for the dioxide, and $532.0 \mathrm{eV}$ for a possible surface hydroxyl species. Additionally, a feature at $\sim 534 \mathrm{eV}$ is observed on samples analyzed after spending significant time in the vacuum system between sputter-cleaning cycles ( $>6 \mathrm{hrs}$.), and as such is likely an adsorbed surface-contaminant from residual gases in the system. These binding energies are consistent with what has been observed previously for the plutonium-oxygen system [3-4,8-9]. All data sets shown have been normalized to the $\mathrm{Pu} 4 \mathrm{f}$ intensity.

The separation of $\mathrm{Pu} 4 \mathrm{f} \mathrm{XP}$ spectra into their individual components can be difficult and subject to variation in the fitted values due to factors such as start and end of the background region, full widthhalf max (FWHM) of each component peak, and Gaussian/Lorentzian character of the component peaks, among other factors. Small changes in these parameters can lead to variation in the determined values of $\mathrm{Pu}^{3+} / \mathrm{Pu}^{4+}$ as well as the $\mathrm{O} / \mathrm{Pu}$ concentration ratios. Great care has been taken to systematically analyze all of the data presented here with the same model (i.e. same peak shapes, FWHM, etc.) and boundary conditions. Based on the signal to noise and variations in the model fit, the error in the concentrations reported here are estimated to be \pm 0.03 for $\mathrm{O} / \mathrm{Pu}$ and $\pm 0.05(5 \%)$ for relative concentrations of $\mathrm{Pu}$ species. This is imperative to be able to qualitatively compare the results and reach valid conclusions regarding the stoichiometry of the prepared oxide films. The $\mathrm{Pu}$ 4f XP spectra for oxidized plutonium metal surfaces can be fitted with a doublet consisting of two asymmetric components for the $\mathrm{Pu}^{3+}$ species $\left(4 \mathrm{f}_{7 / 2}\right.$ and $4 \mathrm{f}_{5 / 2}$ spin-orbit coupled doublet) and symmetric components with satellites for $\mathrm{Pu}^{4+}$. For surfaces showing the presence of the metallic species, a doublet of asymmetric peaks can be used. Both the $4 \mathrm{f}_{7 / 2}$ and $4 \mathrm{f}_{5 / 2}$ transitions were included in the model used to fit the data. Any contribution to the $\mathrm{Pu} 4 \mathrm{f}$ intensity due to the metallic species was subtracted from the $\mathrm{Pu}$ concentration when determining the $\mathrm{O} / \mathrm{Pu}$ concentration ratio to give an accurate estimate of the stoichiometry of the oxidized plutonium species $\left(\mathrm{O} / \mathrm{Pu}^{\mathrm{ox}}\right)$.

\section{Results and Discussion}

Accurate relative sensitivity factors (RSF) for transitions of interest are required for quantification of surface species with XPS. Relative sensitivity factors take into account variables such as the photoelectron cross-section and analyzer transmission efficiency (i.e., transmission function). The RSF's for a given instrument are typically provided by the instrument manufacturer. In the present work, a value of 0.78 was used for the $\mathrm{O} 1 \mathrm{~s}$ data and 0.278 for the $\mathrm{C} 1 \mathrm{~s}$ data (both relative to a $\mathrm{F} 1 \mathrm{~s}$ value of 1), as provided by the instrument manufacturer. However, no RSF was provided for plutonium, as it is a hazardous and radioactive material with strict access and handling requirements.

There are several reports of the $\mathrm{Pu} 4 \mathrm{f}$ RSF in previous studies. One such study used calculated photoelectron cross-sections and a known sensitivity factor (U 4f) to determine the RSF for $\mathrm{Pu} 4 \mathrm{f}$ and other transuranics [10]. A value of 17.87 was reported for the $\mathrm{Pu} 4 \mathrm{f}$ region $\left(10.21\right.$ for the $\left.\mathrm{Pu} 4 \mathrm{f}_{7 / 2}\right)$ relative to a $F$ 1s value of 1 . Another study in which data from oxidized plutonium was used to experimentally determine the $\mathrm{Pu} 4 \mathrm{f}$ RSF reported a value of 92.1 relative to a $\mathrm{C} 1 \mathrm{~s}$ value of 1 [11]. 
These values, when referenced to the same transition, are different by approximately $25 \%$ [11]. This would lead to a corresponding relative concentration variation of $25 \%$ on $\mathrm{Pu}$ surfaces depending on the RSF used. In order to be more confident in the oxygen to plutonium relative concentration ratios reported in the present study, we have also worked to determine a RSF for the $\mathrm{Pu} 4 \mathrm{f}$ transition.

The RSF for plutonium used in this work was estimated by comparison of calculated photoelectron cross-sections [12] to RSF's for other $4 \mathrm{f}$ transitions provided with the instrument from the manufacturer. This resulted in a value of 20.62 for the $\mathrm{Pu} 4 \mathrm{f}$ transition relative to a $\mathrm{F} 1 \mathrm{~s}$ value of 1.00 . Using the RSF for the $\mathrm{C}$ 1s transition provided with the instrument used here (0.278), a value of 74.18 for the $\mathrm{Pu} 4 \mathrm{f}$ transition is obtained when setting the $\mathrm{C} 1 \mathrm{~s}$ value at 1 . The $\mathrm{Pu} 4 \mathrm{f} \mathrm{RSF}$ obtained here is between the two values previously reported [10-11]. Further confidence can be gained in the RSF by comparing quantification results from data with known stoichiometries.

Figure 1 shows spectra $(\mathrm{Pu} 4 \mathrm{f}$ and $\mathrm{O} 1 \mathrm{~s})$ from two plutonium oxide films. Fitting the $\mathrm{Pu} 4 \mathrm{f}$ data shown in the black spectrum indicates a surface consisting of $55 \% \mathrm{Pu}^{4+}$ species $(426.0 \mathrm{eV})$ and $45 \%$ $\mathrm{Pu}^{3+}$ species $(424.4 \mathrm{eV})$. The expected stoichiometry of this film can be estimated assuming oxygen to plutonium concentration ratios of 1.5 for the $\mathrm{Pu}^{3+}$ species and 2.0 for $\mathrm{Pu}^{4+}$. With $55 \% \mathrm{Pu}^{4+}$ and $45 \%$ $\mathrm{Pu}^{3+}$, this film is expected to have an $\mathrm{O} / \mathrm{Pu}$ value of 1.78 . Quantification of this data using the relative
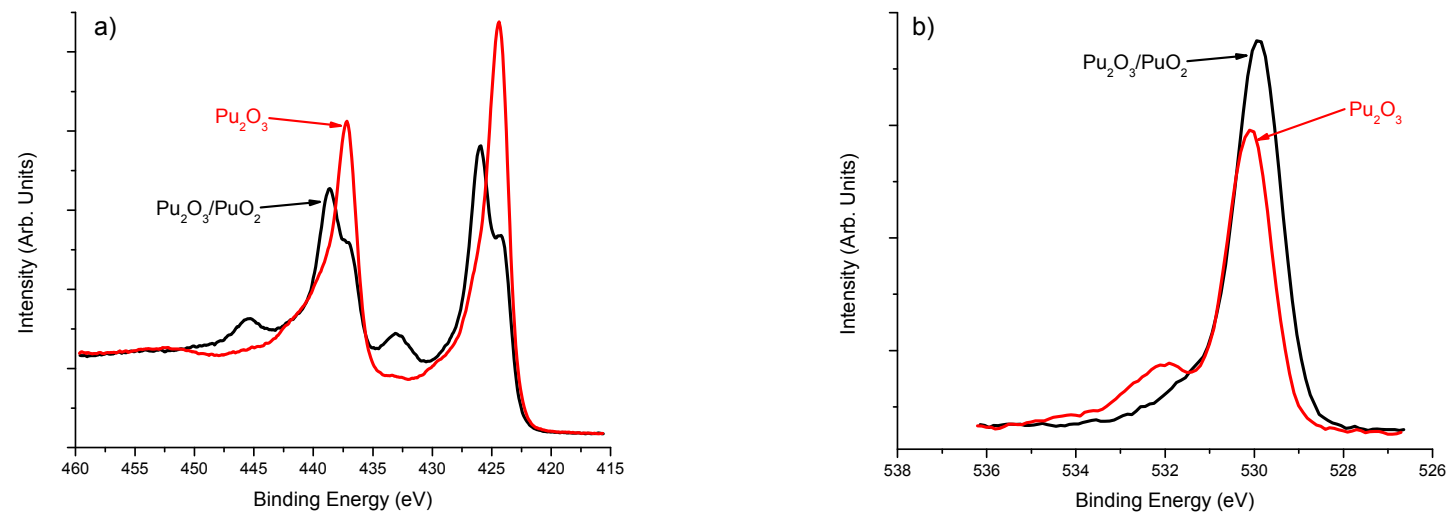

Figure 1. Comparison of a) $\mathrm{Pu} 4 \mathrm{f}$ and $\mathrm{b}$ ) $\mathrm{O}$ 1s spectra from two plutonium oxide films. Red data set from a film consisting nearly entirely of the $\mathrm{Pu}^{3+}$ species and the black data set from a film consisting of approximately $45 \% \mathrm{Pu}^{3+}$ and $55 \% \mathrm{Pu}^{4+}$.

$\mathrm{Pu} 4 \mathrm{f}$ and $\mathrm{O} 1 \mathrm{~s}$ intensities and a $20.62 \mathrm{RSF}$ value for the $\mathrm{Pu} 4 \mathrm{f}$ transition results in an oxygen to plutonium concentration ratio of 1.79 , very close to the expected value. The red spectra in Figure 1 are from a surface consisting nearly entirely of $\mathrm{Pu}^{3+}(98 \%$ to $2 \%$ of the $4+$ species). Similar quantification of this data results in an $\mathrm{O} / \mathrm{Pu}$ concentration ratio of 1.38 , somewhat lower than the expected value of $\sim 1.5$. There are several possible explanations for this low value, as will be discussed later.

The results for exposure of a clean plutonium surface to oxygen at two different pressures are shown in Figure 2. For the exposures performed at $10^{-7}$ Torr in $10 \mathrm{~L}$ increments $(\mathrm{L}=$ Langmuir $=$ $1 \times 10^{-6}$ Torr $\cdot \mathrm{s}$ ), nearly $100 \%$ of the $\mathrm{Pu} 4 \mathrm{f}$ signal corresponds to $\mathrm{Pu}^{3+}$ at exposures greater than $30 \mathrm{~L}$. The $10^{-8}$ Torr exposure data ( $2 \mathrm{~L}$ increments) shows that a small amount $(\sim 20 \%)$ of plutonium metal is still observed at exposures of $30 \mathrm{~L}$. The corresponding $\mathrm{O}: \mathrm{Pu}^{\text {ox }}$ stoichiometric values, while similar for the two experiments, differ significantly from the value typically assumed for plutonium sesquioxide $(\mathrm{O}: \mathrm{Pu}=1.5)$, as illustrated in Figure $2 \mathrm{~b}$. The average oxygen to oxidized plutonium ratio for the $10^{-8}$ Torr incremental exposure is $\sim 1$, regardless of total cumulative oxygen dose. Incremental exposures at $10^{-7}$ Torr of oxygen (up to $80 \mathrm{~L}$ ) also show a maximum $\mathrm{O}: \mathrm{Pu}^{\mathrm{ox}}$ of $\sim 1$. This value remains constant from very thin oxide films at the lowest two exposures of 10 and $20 \mathrm{~L}$, where the oxidized plutonium 
accounts for $\sim 65 \%$ and $\sim 85 \%$ of the $\mathrm{Pu} 4 \mathrm{f}$ signal respectively, to the $80 \mathrm{~L}$ data point where the $\mathrm{Pu} 4 \mathrm{f}$ signal is due entirely to oxidized plutonium. The $\mathrm{C} 1 \mathrm{~s}$ region for both experiments was monitored to ensure the absence of carbon, especially carbide species throughout the duration of the experiments. This figure also seems to indicate that the initial stage of oxidation is somewhat faster at $10^{-8}$ Torr, by the higher initial slope in the growth of the $\mathrm{Pu}^{3+}$ species. However, when the pressure difference of the two experiments is considered (factor of 10 ), the oxidation of plutonium at $10^{-8}$ Torr occurs much more slowly than at $10^{-7}$ Torr.
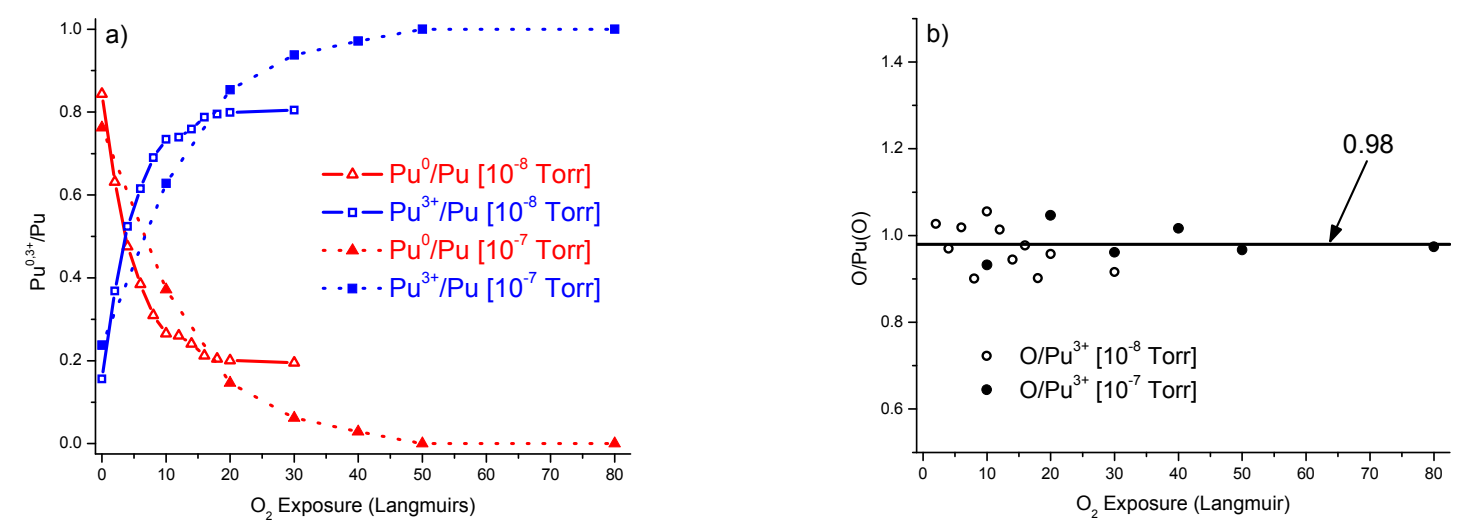

Figure 2. Results from XPS analysis of a clean plutonium metal surface exposed to $\mathrm{O}_{2}$ at $1 \times 10^{-8}$ Torr (open symbols) and $1 \times 10^{-7}$ Torr (solid symbols). The relative concentrations of $\mathrm{Pu}^{0}$ and $\mathrm{Pu}^{3+}$ are shown in a) and the oxygen to oxidized plutonium $\left(\mathrm{Pu}^{3+}\right)$ concentration ratios in $\left.\mathrm{b}\right)$.

Figure 3 shows the results from another set of experiments in which clean plutonium metal surfaces were exposed to $30 \mathrm{~L}$ of oxygen at $1 \times 10^{-8}, 5 \times 10^{-8}$, and $1 \times 10^{-7}$ Torr. These include the same exposure pressures as were used for the studies presented in Figure 2. The oxygen exposures in Figure 3 were performed in a single step, as opposed to multiple steps used in Figure 2 . The $30 \mathrm{~L}$ exposure at $1 \times 10^{-8}$ Torr of oxygen produced an oxide film with an $\mathrm{O} / \mathrm{Pu}^{\mathrm{ox}}$ ratio of 1.08 , close to the value obtained for the films prepared in Figure 2. However, unlike Figure 2, this exposure resulted in oxidation of nearly all $(\sim 95 \%)$ of the plutonium observed in the near-surface region. For a $30 \mathrm{~L}$ exposure at $1 \times 10^{-7}$ Torr of oxygen, a higher $\mathrm{O} / \mathrm{Pu}^{\mathrm{ox}}$ value of 1.3 was observed. The $\mathrm{Pu} 4 \mathrm{f}$ region also shows the absence of metallic $\mathrm{Pu}$, indicating that the analyzed surface is composed entirely of oxide. The exposure at $5 \times 10^{-}$

${ }^{8}$ Torr resulted in an intermediate value for the $\mathrm{O} / \mathrm{Pu}^{\mathrm{ox}}$ of 1.22 . These films were analyzed again after sitting in UHV for 12 hours. The resulting $\mathrm{O} / \mathrm{Pu}^{\text {ox }}$ were 1.08 for the $1 \times 10^{-8}$ Torr exposure and 1.20 for both the $5 \times 10^{-8}$ and $1 \times 10^{-7}$ Torr exposures. All of these $\mathrm{O} / \mathrm{Pu}^{\text {ox }}$ values are significantly lower than the value that is expected for plutonium sesquioxide $(\mathrm{O} / \mathrm{Pu}=1.5)$.

Temperature during oxygen exposure also influences the stoichiometry of plutonium oxide films. Auto-reduction occurs in vacuum at room temperature due to the diffusion of oxygen from $\mathrm{PuO}_{2}$ through the sesquioxide film and subsequent reaction with metal at the interface [6] and can hinder XPS data collection on $\mathrm{PuO}_{2}$ thin films. The exposure of plutonium to oxygen at low temperature stabilizes the $\mathrm{PuO}_{2} / \mathrm{Pu}_{2} \mathrm{O}_{3}$ film on the metal surface by slowing diffusion to a point where the film does not undergo auto-reduction. This allows for data collection from a film in which the composition $(\mathrm{O} / \mathrm{Pu}$ concentration ratio and relative concentrations of plutonium species) within the oxide film does not change. 

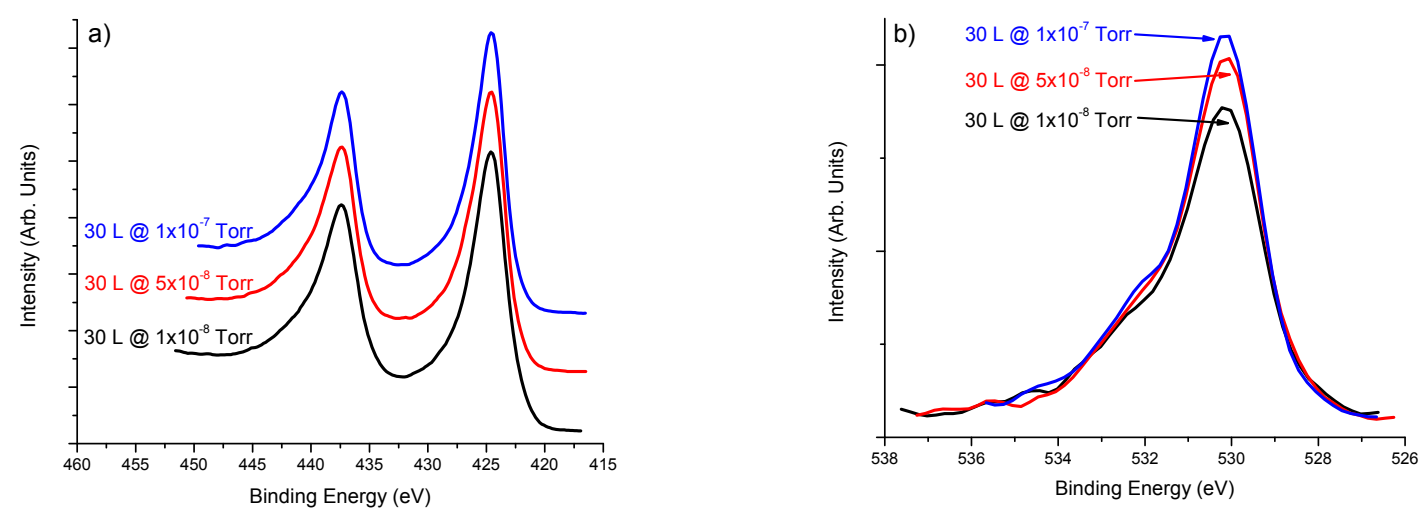

Figure 3. XP spectra from the a) $\mathrm{Pu} 4 \mathrm{f}$ and b) $\mathrm{O} 1 \mathrm{~s}$ regions for three plutonium oxide films grown by exposure to $30 \mathrm{~L}$ of $\mathrm{O}_{2}$ at $1 \times 10^{-8}$ Torr (black data), $5 \times 10^{-8}$ Torr (red data), and $1 \times 10^{-7}$ Torr (blue data).

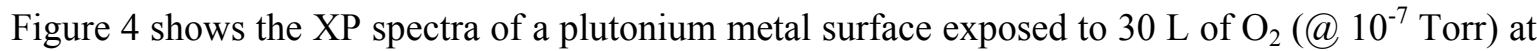
two different temperatures. The red XP spectra shows the resulting data from an oxide film grown at $75^{\circ} \mathrm{C}$ with $30 \mathrm{~L}$ of $\mathrm{O}_{2}$. The $\mathrm{O} / \mathrm{Pu}^{\mathrm{ox}}$ ratio is 1.37 and the corresponding $\mathrm{Pu} 4 \mathrm{f}$ regions show $100 \% \mathrm{Pu}^{3+}$. The black spectrum (as indicated in the figure) illustrates the $\mathrm{O} 1 \mathrm{~s}$ and the $\mathrm{Pu} 4 \mathrm{f}$ region of an oxide film grown under sub-ambient conditions. The sample holder was cooled to $-150{ }^{\circ} \mathrm{C}$, however, as plutonium produces heat due to radioactive decay, the temperature of the sample is not precisely known, but is likely below $-50{ }^{\circ} \mathrm{C}$. This oxide film prepared at sub-ambient temperatures was composed of a $\mathrm{Pu}^{4+} / \mathrm{Pu}^{3+}$ ratio of approximately 1 with a small amount of $\mathrm{Pu}$ metal $(6 \%)$ and an oxygen to oxidized plutonium ratio $\left(\mathrm{O}: \mathrm{Pu}^{\mathrm{ox}}\right)$ of 1.71 .
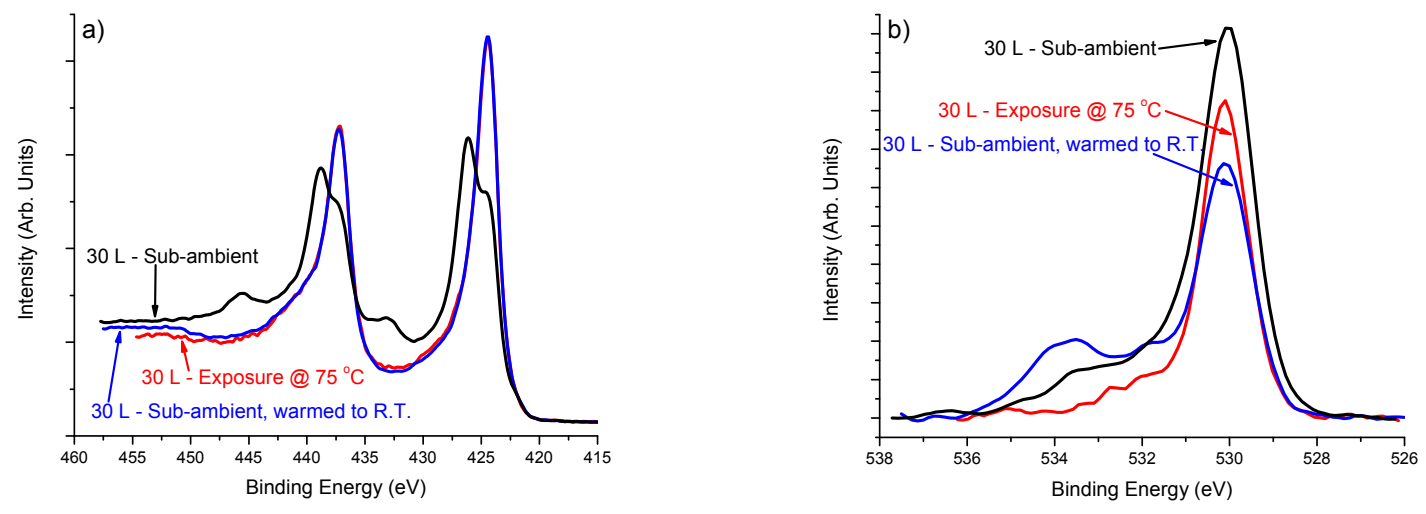

Figure 4. XP spectra from the a) $\mathrm{Pu} 4 \mathrm{f}$ and b) $\mathrm{O} 1 \mathrm{~s}$ regions for two plutonium oxide films grown by exposure to $30 \mathrm{~L}$ of $\mathrm{O}_{2}$ at sub-ambient temperature (black data) and at $75{ }^{\circ} \mathrm{C}$ (red data). Also shown in blue is the data obtained after allowing the subambient sample to warm to room temperature.

Also shown as the blue spectrum in Figure 4, is the resulting spectrum from allowing the film obtained by a $30 \mathrm{~L}$ exposure at sub-ambient temperature (black spectra, discussed above) to warm to room temperature and undergo auto-reduction. The $\mathrm{Pu} 4 \mathrm{f}$ spectrum now consists entirely of the $\mathrm{Pu}^{3+}$ species with no metal or $\mathrm{Pu}^{4+}$ observed. The corresponding $\mathrm{O} 1 \mathrm{~s}$ spectrum yields an $\mathrm{O} / \mathrm{Pu}$ concentration ratio for this film of 1.20. As seen in Figure 4, the $\mathrm{Pu} 4 \mathrm{f}$ spectra for the film grown at 75 ${ }^{\circ} \mathrm{C}$ (red) and for the sub-ambient film warmed to room temperature (gray) are identical, resembling 
what is expected for $\mathrm{Pu}_{2} \mathrm{O}_{3}$, yet the corresponding $\mathrm{O}$ 1s spectra show that they have different oxygen to plutonium stoichiometries.

The existence of an oxide of plutonium lower in stoichiometry than the sesquioxide $\left(\mathrm{Pu}_{2} \mathrm{O}_{3}\right)$ has previously been reported [13]. XRD studies indicated the conversion of $\mathrm{Pu}_{2} \mathrm{O}_{3}$ upon heating $(>250 \mathrm{C})$ to a rocksalt structure historically interpreted as the monoxide (PuO). Subsequent investigations employing XPS concluded that the proposed conversion of $\mathrm{Pu}_{2} \mathrm{O}_{3}$ to $\mathrm{PuO}$ upon heating was likely the formation of plutonium oxycarbide $\left(\mathrm{PuO}_{1-\mathrm{x}} \mathrm{C}_{\mathrm{x}}, \mathrm{x} \sim 0.3\right)$ [14]. The thin oxide films studied here were grown on clean plutonium surfaces at a variety of temperatures, all of which are significantly below the temperatures required for the formation of the oxycarbide. Analysis of the carbon 1s region of the XP spectrum shows no evidence of carbide $(\sim 282 \mathrm{eV})$ before or after oxygen exposure. In addition, the $\mathrm{O} / \mathrm{Pu}$ for these thin films is significantly greater than what would be expected for $\mathrm{PuO}_{1-\mathrm{x}} \mathrm{C}_{\mathrm{x}}$.

Figure 5 offers a comparison of the representative XP spectra for plutonium sesquioxide, plutonium oxycarbide, and the sub-stoichiometric plutonium oxide thin films prepared in this investigation. The black spectra in Figure 5 were obtained after Ar-ion sputtering of a sample that had an oxide/oxycarbide surface layer. While the exact nature of this film is not known, it clearly exhibits the presence of a carbide-type carbon at $282.7 \mathrm{eV}$. Quantification of the $\mathrm{O} 1 \mathrm{~s}$ and $\mathrm{C} 1 \mathrm{~s}$ data for this oxycarbide film yield concentration ratios of $\mathrm{O} / \mathrm{Pu}=1.23$ and $\mathrm{C} / \mathrm{Pu}=0.23$. The absence of significant carbide peaks in the $\mathrm{C} 1 \mathrm{~s}$ region for the higher stoichiometry sesquioxide film $(\mathrm{O} / \mathrm{Pu}=1.37$, blue spectra) as well as the lower stoichiometry film $\left(\mathrm{O} / \mathrm{Pu}^{\mathrm{ox}}=1.08\right.$, red spectra) indicate that these films are relatively pure oxides. The $\mathrm{C} 1 \mathrm{~s}$ region also contains the broad $\mathrm{Pu} 5 \mathrm{p}_{1 / 2}$ feature, making detection of low concentrations of carbon species difficult. Based on the low sensitivity for $\mathrm{C} 1 \mathrm{~s}$ and its spectral overlap we estimate our limit of detection to be $\mathrm{C} / \mathrm{Pu} \sim 0.1$ in the oxide films.
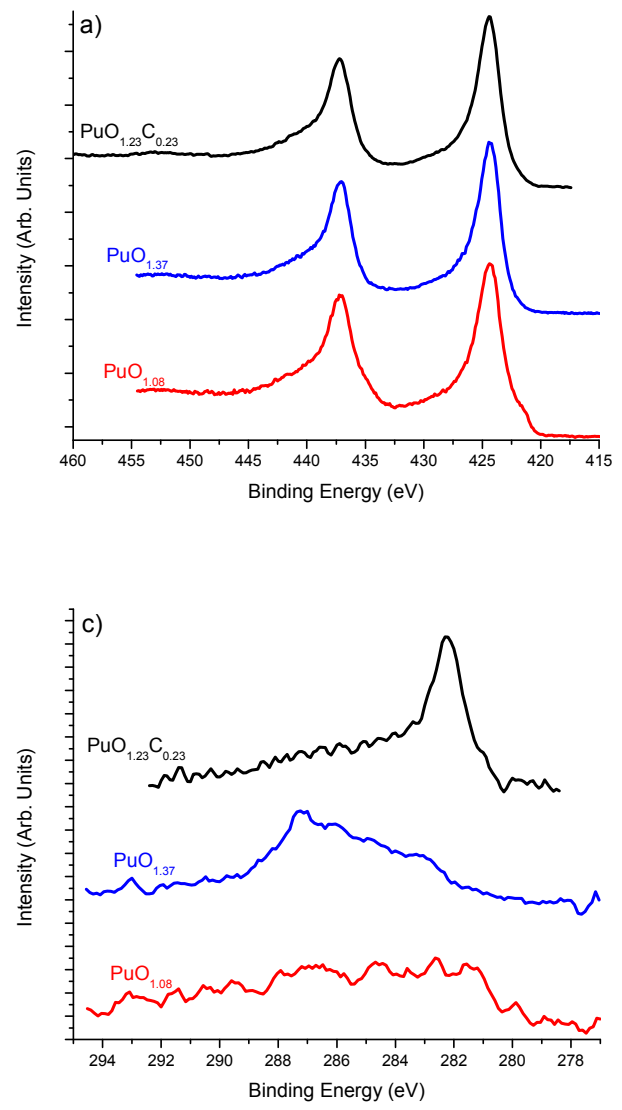

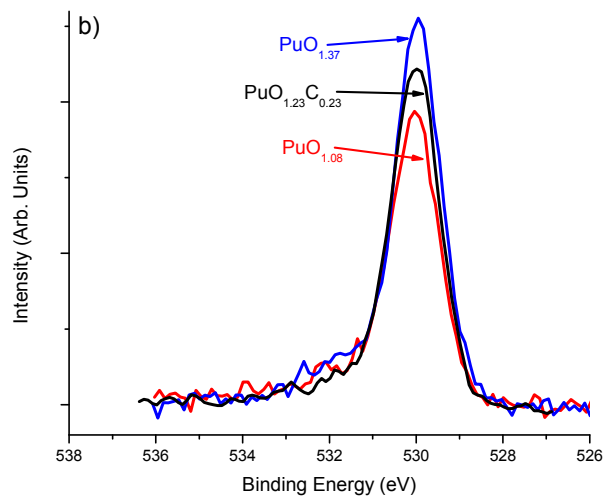

Figure 5. XP spectra from the a) $\mathrm{Pu} 4 \mathrm{f}, \mathrm{b}) \mathrm{O} 1 \mathrm{~s}$, and c) $\mathrm{C} 1 \mathrm{~s}$ regions for a plutonium oxide/oxycarbide film (black data) and two different stoichiometry $\mathrm{Pu}_{2} \mathrm{O}_{3-\mathrm{y}}$ films.

The data presented here clearly indicates that plutonium sesquioxide thin films, under reducing environments, exhibit a wide range of stoichiometries. The $\sim 100 \% \mathrm{Pu}^{3+}$ spectrum in Figure 1 (red) 
shows the highest $\mathrm{O} / \mathrm{Pu}$ ratio observed $(\sim 1.4)$ in this study for oxide-films not containing significant quantities of the $4+$ species. This value is not unreasonable given the ability of $\mathrm{Pu}_{2} \mathrm{O}_{3}$ to support a range of substoichiometric oxygen concentrations under UHV conditions, as shown in the present study. Even if the RSF used in this work is incorrect, resulting in a low $\mathrm{O} / \mathrm{Pu}$ value, all $\mathrm{O} / \mathrm{Pu}$ ratios observed must be scaled accordingly. If it is assumed that the sesquioxide film in Figure 1 must represent stoichiometric $\mathrm{Pu}_{2} \mathrm{O}_{3}$ (i.e., $\mathrm{O} / \mathrm{Pu}=1.5$ ), the corresponding adjustment of the $\mathrm{Pu} 4 \mathrm{f} \mathrm{RSF}$ would still give low $\mathrm{O} / \mathrm{Pu}$ ratios ranging from $\sim 1.1-1.4$ for the oxide films in Figures 2 and 3. This adjustment to the $\mathrm{Pu} 4 \mathrm{f} \mathrm{RSF}$ would also give a higher than expected stoichiometry for the films containing $\sim 50 \% \mathrm{Pu}^{4+}$ shown in Figures 1 and 4, concentration ratios of approximately 1.95 and 1.85 , respectively.

Although the $\mathrm{O} / \mathrm{Pu}$ stoichiometry for the films prepared here exhibit a large range, analysis of the $\mathrm{Pu} 4 \mathrm{f}$ region shows virtually identical spectra for the entire oxygen content range. This indicates that while the formal oxidation state of the plutonium cations in $\mathrm{Pu}_{2} \mathrm{O}_{3}$ must be changing from predominantly $3+$ to $2+$, the electronic structure (as observed with XPS) is not changing significantly. In the absence of data to help elucidate differences in the crystallographic structure of these substoichiometric plutonium oxide films, and the similarity of the $\mathrm{Pu} 4 \mathrm{f}$ XP spectra, they are tentatively described as $\mathrm{Pu}_{2} \mathrm{O}_{3-\mathrm{y}}, \mathrm{y} \sim 0.2-1\left(\mathrm{PuO}_{1.4}-\mathrm{PuO}_{1.0}\right)$.

\section{Conclusions}

Many previous studies on $\mathrm{Pu}$ oxidation and $\mathrm{Pu}$-oxide thin films assume that plutonium sesquioxide is the stable oxide at the oxide-metal interface on plutonium metal. The present work indicates that a sub-stoichiometric plutonium oxide $\left(\mathrm{Pu}_{2} \mathrm{O}_{3-\mathrm{y}}\right)$ exists under reducing environments (i.e., UHV). Based on the high reactivity of plutonium towards oxygen, it is not unreasonable to expect this substoichiometric behavior to occur near the oxide-metal interface in plutonium oxide thin films. While shown to be stable in the bulk phase, plutonium sesquioxide $\left(\mathrm{Pu}_{2} \mathrm{O}_{3}\right)$ films on clean plutonium metal show a significant level of stoichiometric instability under reducing conditions, perhaps similar to what has been shown for plutonium dioxide $\left(\mathrm{PuO}_{2}\right)$ films on plutonium metal.

\section{Acknowledgments}

The authors wish to acknowledge F. J. Freibert, M. Ramos, J. J. Gallegos, A. L. Broach, and T. A. Nothwang for assistance in sample preparation and mounting, as well as the support of the U.S. DOE at LANL under Contract No. DE-AC52-06NA25396.

\section{References}

[1] Butterfield M T, Durakiewicz T, Guziewicz E, Joyce J J, Arko A J, Graham K S, Moore D P and Morales L A 2004 Surf. Sci. 57174

[2] Larson D T and Cash D L 1969 J. Phys. Chem. 732814

[3] Larson D T $1980 \mathrm{~J}$. Vac. Sci. Technol. 1755

[4] Courteix D, Chayrouse J, Heintz L and Baptist R 1981 Solid State Commun. 39209

[5] Gouder T, Seibert A, Havela L and Rebizant J 2007 Surf. Sci. 601 L 77

[6] Morrall P, Tull S, Glascott J and Roussel P 2007 J. Alloy. Compd. 444-445 352

[7] Shirley D A 1972 Phys. Rev. B 54709

[8] Veal B W, Lam D J, Diamond H and Hoekstra H R 1977 Phys. Rev. B 152929

[9] Farr J D, Schulze R K and Neu M P J. Nucl. Mater. 328124

[10] Gouder T and Havela L 2002 Mikrochim. Acta 138207

[11] Morrall P, Roussel P, Jolly L, Brevet A and Delaunay F 2009 J. Nucl. Mater. 38515

[12] Scofield J H 1976 J. Electron Spectrosc. 8129

[13] Terada K, Meisel R L and Dringman M R 1969 J. Nucl. Mater. 30340

[14] Larson D T and Haschke J M 1981 Inorg. Chem. 201145 